\title{
Fire Resistance of Bamboo Fiber Reinforced SCC with GGBS and Alccofine Partially in Place of Cement
}

\author{
S. Kavitha ${ }^{1}$ and T. Felix Kala ${ }^{2}$ \\ ${ }^{1}$ Associate Professor, ACS College of Engineering, Bangalore, India \\ ${ }^{2}$ Dean, Dr. M.G.R Educational Research Institute, Chennai, India \\ DOI: https://doi.org/10.34293/acsjse.v1i1.6
}

\begin{abstract}
Fire accidents have become a common occurrence which results in loss of lives and property, in preliminary stage while selecting material and designing, the performance of every structure against condition of fire has to be considered. The fire resistance is important durability characteristic which evaluate the quality of the material. In this investigation, fire resistance capacity of the NSCC with GGBS and alccofine and the BFRSCC with GGBS and alccofine is evaluated by considering the weight and strength parameters before and after exposing to the temperatures of $200^{\circ} \mathrm{C}, 400^{\circ} \mathrm{C}, 600^{\circ} \mathrm{C}, 800^{\circ} \mathrm{C}$ and $1000^{\circ} \mathrm{C}$ for one hour duration. The test for assessing compressive strength for $150 \mathrm{~mm} \times 150 \mathrm{~mm} \times 150 \mathrm{~mm}$ concrete requires cube of and allowed in water for 28 days. The bamboo fibers of 1\% (length to diameter ratio=40) of $4.9 \mathrm{~mm}$ measurement lengthwise to the mass of cement are mixed to the SCC where cement is partially placed with 30\% of GGBS along with 10\% Alccofine. As noted from the results the strength decreased by increasing the temperatures. Less strength is decreased at lesser elevated temperatures but massive reduction occurred in the higher elevated temperatures. The weight and compressive strength of the material has minor reduction till $800 \mathrm{oc}$ which is acceptable as a building material.
\end{abstract}

Keywords: Fire Résistance; Alccofine; GGBS; FRC; high strength; Self Compacted concrete.

\section{INTRODUCTION}

In the field of concrete technology, SCC is relatively new technique. SCC is a novel approach to solving the issue of dense reinforcement in concrete. Because of its properties, such as pumpability, fill, flow ability, and ability to manufacture concrete manufacturing more industrialised, SCC is unique. It becomes important to build a production system that is free of compaction, thus lowering overall costs. Egyptians used animal hair and straw as reinforcement for walls with bricks in their homes, which is when the idea of fibres in a brittle mix was first documented. These fibres can have a range of mechanical properties as well as design possibilities. Natural plant fibres are now commonly used as a substitute for manufacturing fibres in engineering fields. To raise thos, however, less potential is needed.

Bamboo, which has characteristics of both grass and wood, is the answer to this issue. Due to heavy fibre bundles, it is extraordinarily tough in the longitudinal direction. As a result, cement is expensive, and in light of global warming, Alccofine and GGBS are being used to partially substitute cement, bamboo fibres called BFRSCC with alccofine and GGBS.

Imperviousness to fire is a check of a structure component's capacity to stand firm for fire, ordinarily the measure of time the component can withstand certain models while exposed to a standard imperviousness to fire test. An underlying segment, like a shaft or a 
section, a non-primary component, like a parcel or entryway, or a blend, like a story or burden bearing divider, are for the most part instances of building components.

Imperviousness to fire is a property doled out to building components made of a solitary material or a mix of materials. An imperviousness to fire rating is the degree of imperviousness to fire doled out to a structure component dependent on a test or other endorsement framework. Strength, trustworthiness, and protection are the principle disappointment rules for imperviousness to fire. Subsequently, the imperviousness to fire of the BFRSCC (concrete supplanting GGBS and Alccofine) needs to explore.

\section{EXPERIMENTAL INVESTIGATIONS}

\section{Used Materials}

\section{Cement}

In the experimentation, OPC-53 grade was used. It was tested in accordancewith IS 4031:1988 and confirmed in accordance with IS 12269:2004.

Table 1: Physical Properties of Cement

\begin{tabular}{|c|c|c|c|c|}
\hline No. & Properties & Testing Method & Results & $\begin{array}{c}\text { Limitations As } \\
\text { per IS 12269-2004 }\end{array}$ \\
\hline 1 & Normal consistency in $(\%)$ & $\begin{array}{l}\text { Vicat apparatus } \\
\text { (IS: 4031Part - 4) }\end{array}$ & $33 \%$ & $30-35 \%$ \\
\hline 2 & Specific gravity & $\begin{array}{c}\text { Sp. Gr bottle } \\
\text { (IS: 4031Part - 4) }\end{array}$ & 3.12 & $\leq 3.15$ \\
\hline 3 & IST & \multirow{2}{*}{$\begin{array}{l}\text { Vicat apparatus } \\
\text { (IS: } 4031 \text { Part - 5) }\end{array}$} & $42 \mathrm{Min}$ & $>30$ \\
\hline 4 & FST & & 221 Min & $<600$ \\
\hline 5 & Fineness & $\begin{array}{l}\text { Sieve test on } 90 \mu \text { Sieve } \\
\text { (IS: } 4031 \text { Part - 1) }\end{array}$ & $6 \%$ & $<10 \%$ \\
\hline
\end{tabular}

\section{Coarse aggregates}

Crushed granite aggregate from the local area, which can pass direct $12 \mathrm{~mm}$ and containing $4.75 \mathrm{~mm}$ which has applied for entire concrete mix.

Table 2: Physical characteristics of Course Aggregate

\begin{tabular}{|c|c|c|c|}
\hline No & Physical properties & Results & \multirow{2}{*}{ Code of reference } \\
\hline 1 & Specific Gravity & 2.64 & \multirow{3}{*}{ IS 2386 Part 3-1986 } \\
\hline 2 & Water Absorption & $0.16 \%$ & \\
\hline 3 & Bulk Density $\left(\mathrm{Kg} / \mathrm{m}^{3}\right)$ & 1365 (loose) 1440 (rodded) \\
\hline 4 & Finess Modulus & 2.82 & \\
\hline 5 & Impact Value & $9.77 \%$ & \\
\hline 6 & Loss Angles Abrasion & $36.1 \%$ & \\
\hline 7 & Flakiness Index & $15 \%$ & \\
\hline 8 & Elongation Index & $61.9 \%$ & \\
\hline
\end{tabular}




\section{Fine Aggregates}

Fine aggregate is described as aggregate with a particle size of less than $4.75 \mathrm{~mm}$. The precise collective contented of the mixture must in the scope of $1 / 4$ th to $1 / 3 \mathrm{rd}$ of the entire quantity. Precise collective is extremely essential in reducing separation. All concrete mixes were made with locally available sand that had been sieved through a $4.75 \mathrm{~mm}$ sieve. As per IS: 383-1970, the aggregates were used in zone I.

Table 3: Physical characteristics of Fine aggregate

\begin{tabular}{|c|c|c|c|}
\hline No & Physical Properties & Results & Code of Reference \\
\hline 1 & Specific Gravity & 2.6 & \multirow{2}{*}{ IS 2386 Part 3-1963 } \\
\hline 2 & Bulking & $11 \%$ & \\
\hline 3 & Bulk Density & 1434(loose) 1601 (rodded) & \\
\hline 4 & Finess Modulus & 2.79 & IS383-1970 \\
\hline
\end{tabular}

\section{Super Plasticizer}

The chemical mix that is utilized to improve workability without the use of additional water. Glenium B233, a commercially available superplasticizer, was used in this study.

Table 4: Characteristics of Glenium B233 (Super plasticizer)

\begin{tabular}{|l|l|l|}
\hline \multicolumn{1}{|c|}{ Parameters } & \multicolumn{1}{|c|}{ Results } & \multicolumn{1}{c|}{$\begin{array}{c}\text { Specifications } \\
\text { (As Per IS 9103) }\end{array}$} \\
\hline Physical State & Light Brown Liquid & Light Brown Liquid \\
\hline $\begin{array}{l}\text { Chemical Name of Active } \\
\text { Ingredient }\end{array}$ & $\begin{array}{l}\text { Polycarboxylate } \\
\text { Polymers }\end{array}$ & $\begin{array}{l}\text { Polycarboxylate } \\
\text { Polymers }\end{array}$ \\
\hline Relative Density At 25 C & 1.079 & $1.08 \pm 0.02$ \\
\hline $\mathrm{Ph}$ & 6.89 & Min.6 \\
\hline Chloride Ion Content (\%) & 0.0080 & Max 0.2 \\
\hline Dry Material Content & 35.12 & $34( \pm 5 \%)$ \\
\hline
\end{tabular}

\section{Bamboo Fibers}

Bamboo filaments are common strands extricated from the bamboo tree and utilized as a substitute for regular plant filaments, with numerous benefits including minimal effort, low thickness, eco-invitingness, supportability, and biodegradability. In this investigation, bamboo filaments were extricated utilizing a mechanical technique. An examining electron microscopy test was performed to decide the microstructure of bamboo filaments, disappointment examination, and the measurement of bamboo fiber. Figures 1 through 5 portray different phases extraction of bamboo fiber. 


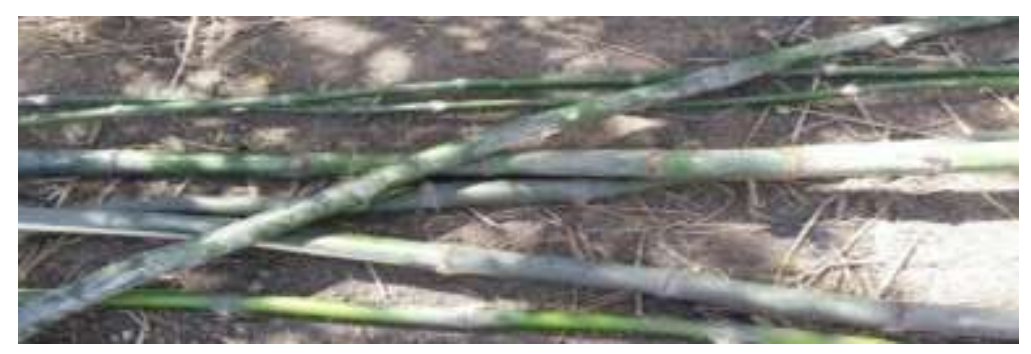

Figure 1: Various age of raw bamboo

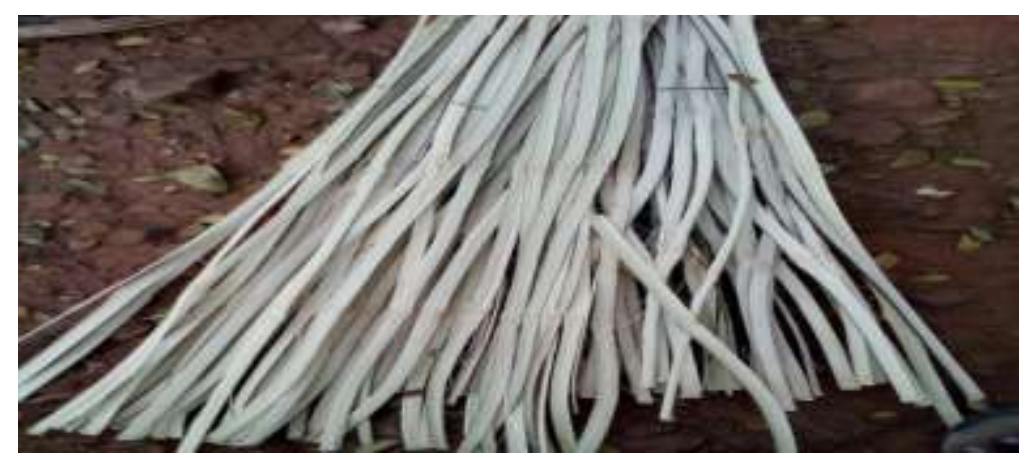

Figure 2: Bamboo-longitudinal stripes

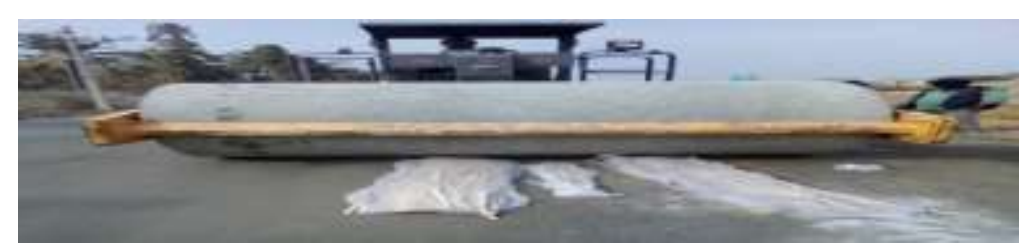

Figure 3: Under roller - striped bamboo

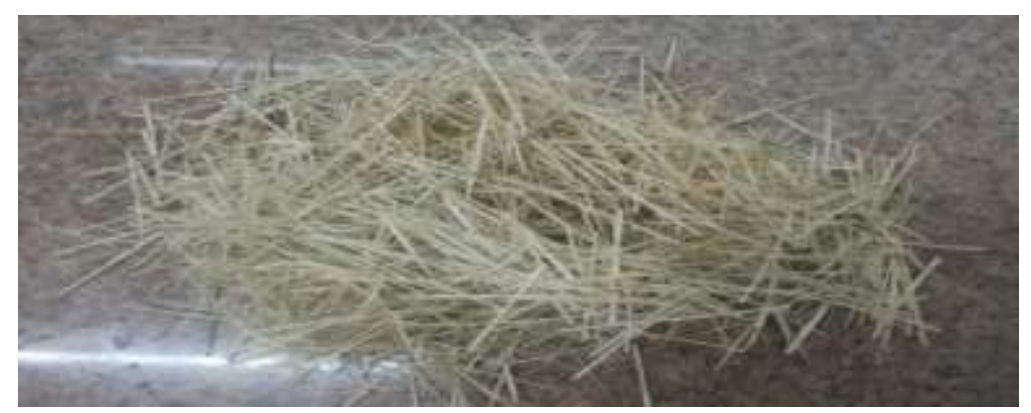

Figure 4: Dia $1.156 \mathrm{~mm}$ fiber of aspect ratio (l/d)-40

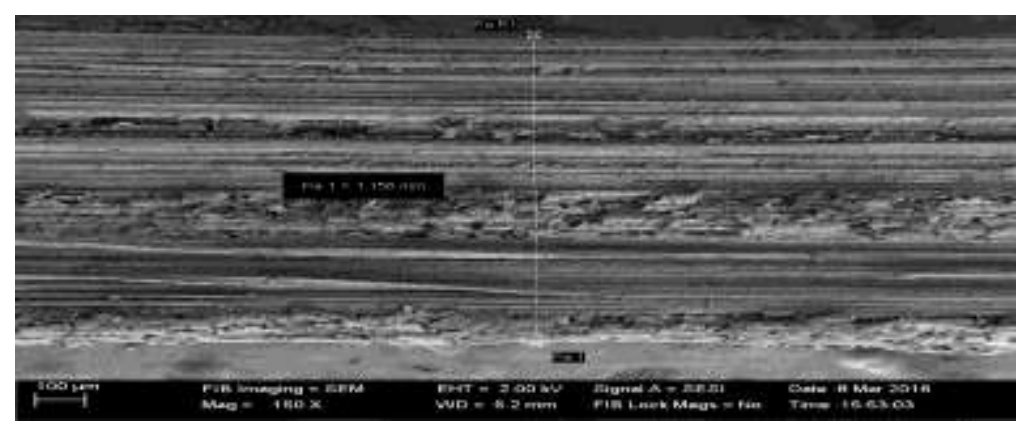

Figure 5: SEM picture of bamboo fiber diameter $1.156 \mathrm{~mm}$ 


\section{Alccofine}

Alccofine is a high glass substance, reactivity, and uncommon item shaped through the controlled granulation technique. The crude material is fundamentally with low calcium silicates This mix, alongside other painstakingly picked fixings, brings about a controlled molecule size appropriation.

\section{GGBS: Filler}

A substantial amount of research has been conducted in the last decade to address the effectiveness of GGBS. Table 4 displays the Physical characteristics of GGBS.

Table 4: Physical Characteristics s of GGBS

\begin{tabular}{|c|l|l|}
\hline S. No & \multicolumn{1}{|c|}{ Physical Properties } & \multicolumn{1}{|c|}{ Ggbs } \\
\hline 1 & Specific Gravity & 2.7 \\
\hline 2 & Fineness Modulus & 2.79 \\
\hline 3 & Bulk1density (Loose, Compacted) $\left(\mathrm{Kg} / \mathrm{M}^{3}\right)$ & 1347,1479 \\
\hline
\end{tabular}

\section{RESULT}

\section{Fresh Properties of BFRSCC}

Table 5 shows the results of the workability tests. Slump values range from $655 \mathrm{~mm}$ for regular self-compacting concrete to $725 \mathrm{~mm}$ for $1 \%$ fibre contented. the slump values in relation to the fibre content It has been discovered that the results confirm the minimum and maximum recommended values. The slump flow increases linearly as the fibre content increases. As a result, bamboo fibres are appropriate for SCC because they meet almost EFNARC's workability recommendations.

Table 5: Workability of Fresh BFRSCC

\begin{tabular}{|c|l|c|c|c|c|}
\hline \multirow{2}{*}{ S. No } & \multirow{2}{*}{ Description } & \multirow{2}{*}{ NSCC } & \multirow{2}{*}{ BFRSCC } & \multicolumn{2}{|c|}{ EFNARC Values } \\
\cline { 4 - 6 } & & & & Min & Max \\
\hline 1 & Slump Flow (mm) & 655 & 725 & 650 & 800 \\
\hline 2 & T50 Cm Slump Flow (S) & 4 & 2 & 2 & 5 \\
\hline 3 & V-Funnel (S) & 9 & 7 & 6 & 12 \\
\hline 4 & V-Funnel T5 Min (S) & 13 & 8 & 0 & 3 \\
\hline 5 & L-Box (H2/H1) & 0.8 & 0.95 & 0.8 & 1 \\
\hline
\end{tabular}

\section{Durability Characteristics of BFRSCC}

\section{Fire Resistance Characteristics}

The fire resistance is an important durability characteristic that determines the material's quality. In this study, the fire resistance capacity of normal SCC with GGBS and alccofine and BFRSCC with GGBS and alccofine is evaluated by taking weight and strength parameters before and after exposure to temperature of $200{ }^{\circ} \mathrm{C}, 400{ }^{\circ} \mathrm{C}, 600{ }^{\circ} \mathrm{C}, 800{ }^{\circ} \mathrm{C}$ and $1000^{\circ} \mathrm{C}$ for one hour duration. The compressive strength test for concrete uses a cube 
specimen of $150 \mathrm{mmX} 150 \mathrm{~mm}$ size that has been allowed to curative in water and mortal for 28 days before being loaded in a CTM.

Table 6 displays the effect of the Compressive strength test. It exhibited by the above results, increasing the temperatures reduced the strength. Less strength is lost at lower elevated temperatures, but a massive loss occurs at higher elevated temperatures. figure 6 to figure 11 shows the conduction of experiment. Table 6 and Figure 12 show the weight variation with temperature for one hour of NSCC and BFRSCC. The variation of compressive strength with temperature for one hour of NSCC and BFRSCC is shown in table 7 and figure 13.

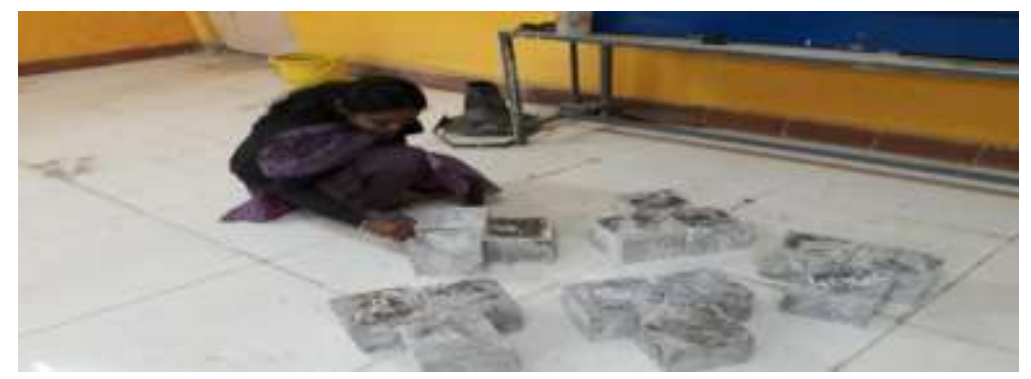

Figure 6: Specimens before exposing to the different temperatures

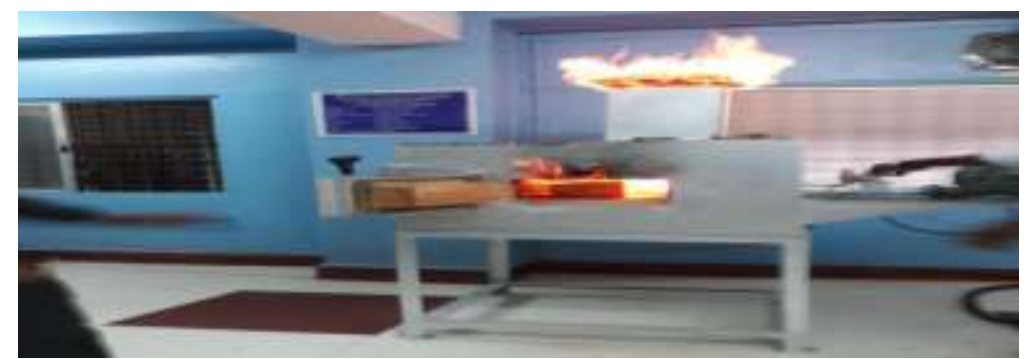

Figure 7: Specimen under elevated temperature in the furnace

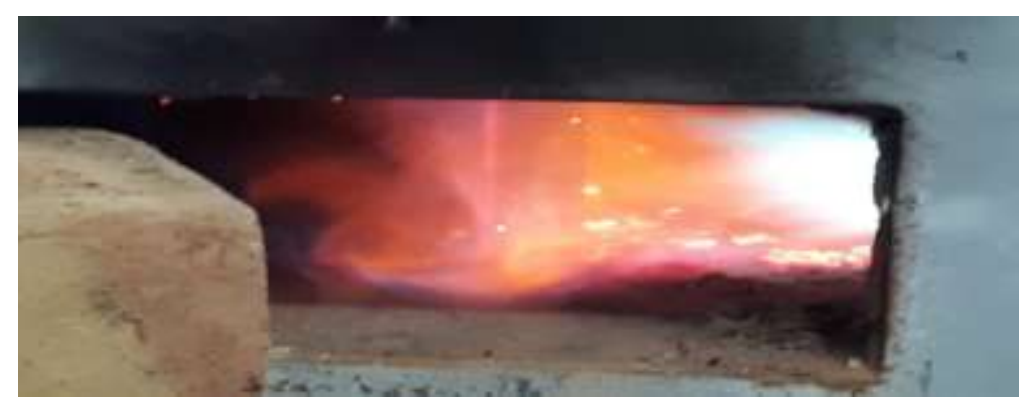

Figure 8: Specimen under elevated temperature of $1000^{\circ} \mathrm{C}$ in the furnace 


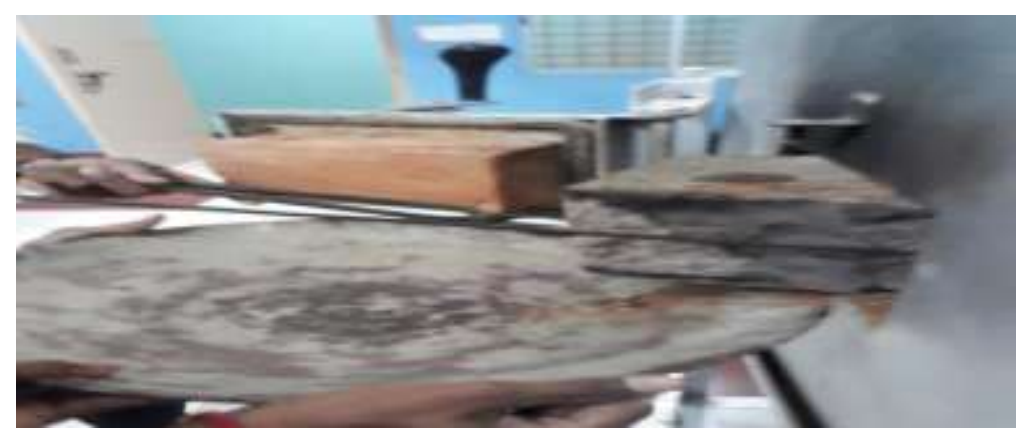

Figure 9: Specimen after elevated temperature of $1000^{\circ} \mathrm{C}$ in the furnace

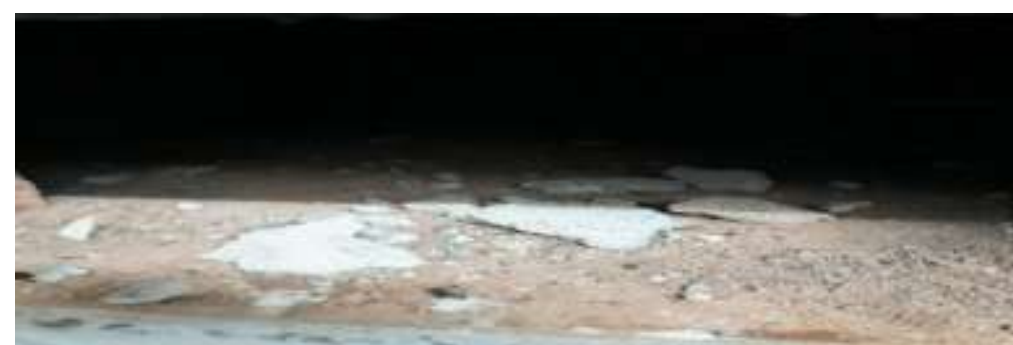

Figure 10: Specimen spallings under elevated temperature of $1200^{\circ} \mathrm{C}$ in the furnace

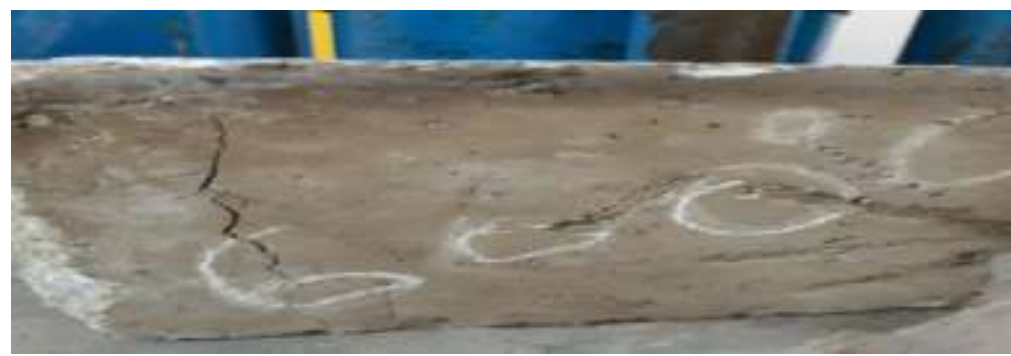

Figure 11: Specimen after testing in the compressive strength testing machine

Table 6: Variation of weight before and after exposing to elevated temperature for 1 hour duration

\begin{tabular}{|c|c|c|c|c|c|}
\hline \multirow{2}{*}{ S. No } & \multirow{2}{*}{$\begin{array}{c}\text { Temperature } \\
\text { Maintained for 1 hour }\end{array}$} & \multicolumn{2}{c|}{ NSCC } & \multicolumn{2}{c|}{ BFRSCC } \\
\cline { 3 - 6 } & & \multicolumn{2}{c|}{ Weight (KG) } & \multicolumn{2}{c|}{ Weight (KG) } \\
\cline { 3 - 6 } & Before & After & Before & After \\
\hline 1 & 0 & 7.79 & 7.79 & 7.96 & 7.96 \\
\hline 2 & 200 & 7.89 & 7.87 & 8.09 & 8.01 \\
\hline 3 & 400 & 7.82 & 7.8 & 7.96 & 7.91 \\
\hline 4 & 600 & 7.76 & 7.71 & 7.90 & 7.84 \\
\hline 5 & 800 & 7.85 & 7.75 & 8.01 & 7.81 \\
\hline 6 & 1000 & 7.81 & 7.7 & 8.09 & 7.89 \\
\hline
\end{tabular}




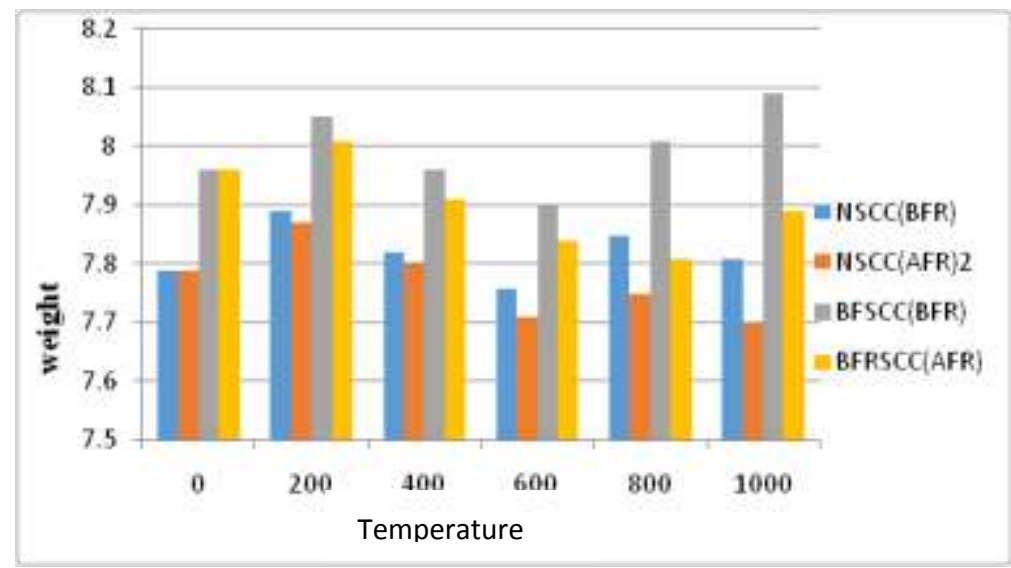

Figure 12: Variation of weight before and after exposing to elevated temperature for 1 hour duration

Table 7: Variation of compressive strength before and after exposing to elevated temperature for 1 hour duration

\begin{tabular}{|c|c|c|c|c|c|}
\hline \multirow{3}{*}{ S. No } & \multirow{3}{*}{$\begin{array}{c}\text { Temperature } \\
\text { Maintained for } 1 \text { hour }\end{array}$} & \multirow{2}{*}{\multicolumn{2}{|c|}{$\begin{array}{c}\text { NSCC } \\
\text { Compressive Strength } \\
\left(\mathrm{N} / \mathrm{mm}^{2}\right)\end{array}$}} & \multirow{2}{*}{\multicolumn{2}{|c|}{$\begin{array}{c}\text { BFRSCC } \\
\text { Compressive Strength } \\
\left(\mathrm{N} / \mathbf{m m}^{2}\right)\end{array}$}} \\
\hline & & & & & \\
\hline & & Before & After & Before & After \\
\hline 1 & 0 & 33.1 & 33.1 & 36.9 & 36.9 \\
\hline 2 & 200 & 32.9 & 31.4 & 35.7 & 34.9 \\
\hline 3 & 400 & 32.1 & 31.5 & 35.2 & 34.2 \\
\hline 4 & 600 & 34.2 & 32.6 & 36.9 & 32.9 \\
\hline 5 & 800 & 33.2 & 30.1 & 35.9 & 29.9 \\
\hline 6 & 1000 & 32.1 & 29.9 & 34.9 & 28.2 \\
\hline
\end{tabular}

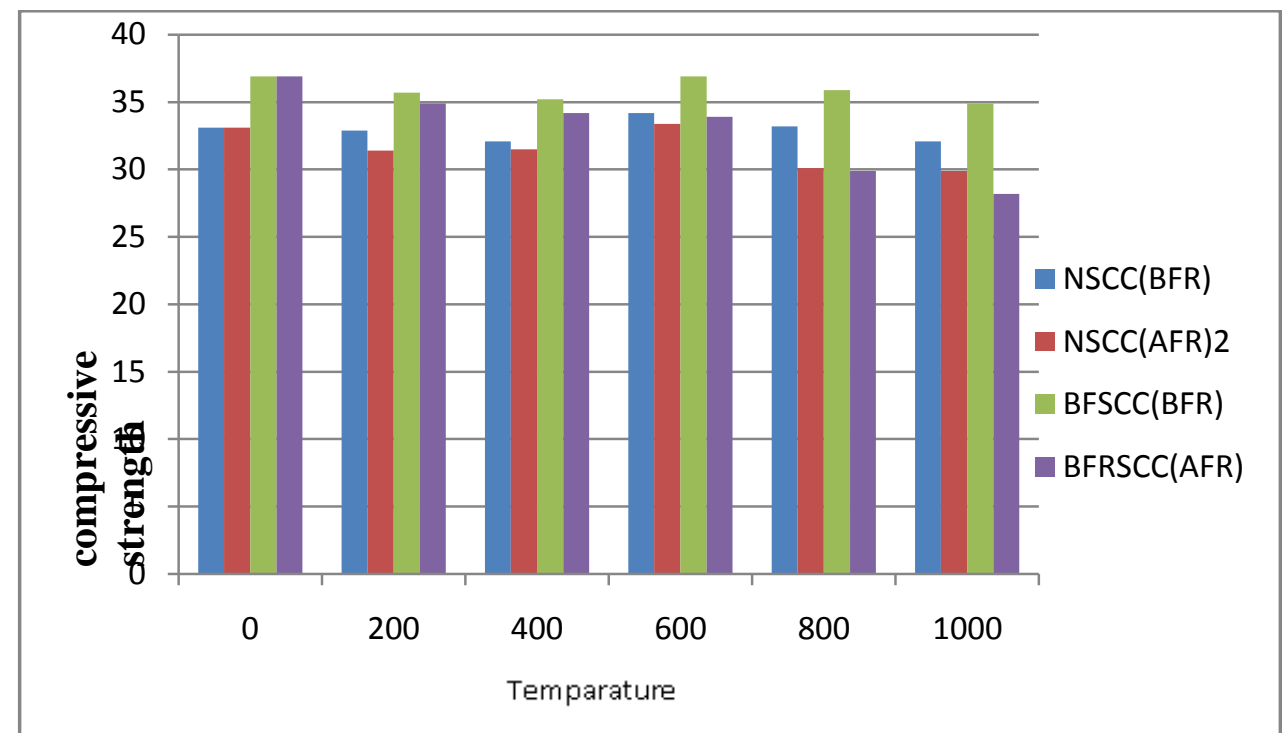

Figure 13: Variation of compressive strength before and after exposing to elevated temperature for 1 hour duration 


\section{CONCLUSION}

The conclusions are:

- Based on experimental results, it was determined that the presence of fibres in the proposed concrete didn't show any reduction in the weight and strength of the concrete up to $800^{\circ} \mathrm{C}$.

- The fireproof test outcomes show that there is a decrement in compressive strength in the wake of warming the solid at 800 degrees Celsius for 60 minutes. Without the fiber the strength decreases by $10 \%$ over its original strength and it is reduced by $18 \%$ for $1 \%$ usage in fibre content. This decrement in strength is caused by the fibres melting at high temperatures and creating pores for the dissipation of vapour pressure. The water in the mix evaporates into water vapor, while the sand and gravel become molten lava. So the strength reduced automatically.

- This investigation shows bamboo fiber reinforced self compacting concrete gives moderate resistance to fire while compare to normal self compacting concrete. So, bamboo fibers can be suggested to use as reinforcement in the concrete.

\section{REFERENCES}

[1] Nan Su, Kung-Chung Hsu, and His-Wen Chai G. "A simple mix design method for self-compacting concrete," Cement and Concrete Research, 2001.

[2] Hajime Okamura, and Masahiro1ouchi. "Self Compacting Concrete," Journal of advanced concrete technology, 2003, pp. 5-15.

[3] Nguyen Tien Phog, Toru Fujii, Bui Chuong, and Kazuya Okubo. "study on how effectively extract bamboo fibres from raw bamboo and waste water treatment," Journal of Materials Science Research, 2012, pp. 145-150.

[4] P. Zakikhani, R. Zahari, M.T.H. Sultan, and D.L. Majid. "Bamboo Fibre Extraction and its reinforced polymer composer material," International Journal of Chemical, Molecular, Nuclear, Materials and Metallurgical Engineering, 8(4), 2014.

[5] Masakazu Terai \& Koichi Minami. "Research and development on bamboo reinforced concrete structure," 2012.

[6] Chandramouli, K, Srinivasa Rao, P, Pannirselvam, N, Seshadri Sekhar, T, and Sravana, Priyadrashini, T.P. "Strength and durability characteristic of glass fibre concrete," International Journal of Mechanics of Solids, 5(1), 2010, pp. 15-26.

[7] C. Selin Ravikumar, and T.S. Thandavamoorthy. "Glass Fibre Concrete Investigation on Strength and Fire Resistant Properties," IOSR Journal of Mechanical and Civil Engineering (IOSR-JMCE), 9(3), pp. 21-25. 